\title{
Prevalence and risk factors for skin lesions on legs of dairy cattle housed in freestalls in Norway
}

\author{
C. Kielland, ${ }^{* 1}$ L. E. Ruud,† A. J. Zanella, ${ }^{*} \dagger$ and O. Østerås ${ }^{*}$ \\ *Department of Production Animal Clinical Sciences, Norwegian School of Veterinary Science, Oslo, Norway \\ †Department of Animal and Aquacultural Sciences, Norwegian University of Life Sciences, Âs, Norway
}

\begin{abstract}
Appropriate indoor housing facilities for dairy cattle promote improved animal welfare. Skin alterations are an indicator of dysfunctional housing. The purpose was to determine the relationship between different housing design and skin lesions, hence providing farmers more insight into how to reduce the occurrence of lesions. A cross-sectional study was conducted on 2,335 animals in 232 Norwegian freestall-housed dairy cattle from September 2006 to June 2007. A model was established to investigate risk factors related to the presence of lesions including hair loss, swelling, and wounds on the legs of dairy cattle. Separate models were developed to investigate risk factors related to the presence of knee and hock lesions. Previously described risk factors were included in the models, together with a questionnaire addressing the attitude of the farmer toward the animals. Mean $( \pm \mathrm{SD})$ prevalence for hock lesions was 60.5 $\pm 21.2 \%$ with a median value of $64 \%$. The prevalence for knee lesions was $35.3 \pm 25.7 \%$ with a median of $30 \%$. Cows in herds with a soft freestall base had an odds ratio (OR) for knee and hock lesions of $0.22(0.06$ to 0.73 ) and 0.62 (0.48 to 0.80 ), respectively, compared with those in herds with a harder freestall base, such as concrete and compact rubber mats. There was an increased risk of hock lesions when the length in the lying area in a double-row freestall was $>250 \mathrm{~cm}$ (OR = $2.96 ; 1.02$ to 8.60 ) compared with $\leq 250 \mathrm{~cm}$, and when the length of the lying area against a wall was $>260$ $\mathrm{cm}(\mathrm{OR}=2.11 ; 1.53$ to 2.90$)$ compared with $\leq 260 \mathrm{~cm}$. The risk for knee lesions increased if a row against a wall was $>270 \mathrm{~cm}(\mathrm{OR}=1.72 ; 1.09$ to 2.72$)$ compared with $\leq 270 \mathrm{~cm}$. Hock lesions were associated with lame cows $(\mathrm{OR}=5.76 ; 1.14$ to 29.18$)$ versus nonlame cows, and with cows in their second or higher parity $(\mathrm{OR}=$ $1.27 ; 1.06$ to 1.52 ) versus cows in their first parity. Knee lesions were associated with farmers' negative attitudes toward animals in pain $(\mathrm{OR}=3.28 ; 1.79$ to 6.03$)$ versus
\end{abstract}

Received April 14, 2009

Accepted July 16, 2009.

${ }^{1}$ Corresponding author: camilla.kielland@veths.no those with positive attitudes; cows in the beginning of their lactation $(\mathrm{OR}=1.84 ; 1.24$ to 2.74$)$ versus those at the end of their lactation; and tall animals $(\mathrm{OR}=1.27$; 1.00 to 1.61) versus shorter animals. These results show that freestall design is important with respect to skin lesions as are the characteristics of individual animals and the farmer.

Key words: dairy cattle, skin lesion, freestall, welfare

\section{INTRODUCTION}

Since 2004, it has been prohibited to build new tiestall barns under Norwegian regulations (Norwegian Food Authorities, 2004) and as a result, there has been a rapid increase in the number of freestall housing systems. Shortcomings in design may cause injuries, giving rise to behavioral restriction, and therefore compromising animal welfare. Freedom from pain and injuries and the ability to perform natural behaviors are important factors in securing animal welfare at the farm level (Brambell Committee, 1965).

Skin lesions on the legs of cattle likely occur on areas where there are protrusions. When animals lie down, the soft tissue is compressed between these protrusions and the lying surface, resulting in an interruption of perfusion to the tissue (Zurbrigg et al., 2005). Typical lesion locations in cattle are the joints, including carpal (knee), fetlock, tarsal (hock), and hip (Weary and Taszkun, 2000); also, skin lesions occur around the articulation genus (stifle; Huxley and Whay, 2006). Lesions around the hock are common, and can range from a small area of hair loss to open wounds, and swelling can sometimes be seen on the entire joint (Weary and Taszkun, 2000).

Recording the occurrence of skin lesions has been used in on-farm dairy cow welfare protocols (Main et al., 2003). Lesions over joints occur because of deficiencies in the floor surface (Huxley and Whay, 2006). Recently, Sogstad et al. (2005) reported more swollen hocks in lame animals, a finding supported by Regula et al. (2004). 
Rutherford et al. (2008) investigated hock lesions in cattle on organic and nonorganic farms in a multifactorial study. They found that cows on organic farms had fewer hock lesions than cows on conventional farms. Limited feeding space per cow, low total standing area, reduced passageway cleanliness, and type of bedding were positively associated with the prevalence of hock lesions. A clear effect of season was observed, with more hock lesions in the spring than in the fall. Parity, lying time, type of freestall base, herd size, BCS, DIM, freestall dimensions, and milk production were some of the risk factors reported previously (Busato et al., 2000; Weary and Taszkun, 2000; Rutherford et al., 2008).

Nevertheless, housing design and animal-based measurements cannot explain all of the factors associated with skin lesions. The attitudes of farmers toward animals indirectly affect their handling of cattle (Coleman et al., 1998). The human-animal relationship influences cattle productivity and welfare (Hemsworth et al., 2000). Kielland et al. (2008) developed a new instrument to assess the relationship between attitudes and empathy of dairy farmers toward cows. Some aspects of that instrument, which assessed the attitude profile of farmers, were included in the analysis of the present study.

The purpose was to provide farmers with information on the effect of specific housing-design characteristics on skin lesions to yield more insight into how to reduce the occurrence of these lesions.

\section{MATERIALS AND METHODS}

\section{Study Population}

This study was part of a larger descriptive and crosssectional project on freestall housing in Norwegian dairy herds (E. Simensen, retired from Norwegian School of Veterinary Science, Oslo, Norway; personal communication). A list of 2,400 herds that were presumed to house cattle in freestalls was obtained from a questionnaire sent to all dairy advisers in Norway. Farmers had to fulfill the inclusion criteria, which involved their willingness to participate, having herd size $>20$ standardized cow-years (based on the year 2005), having barns built between 1995 and 2005, and having confirmed use of freestalls. Additionally, data were stratified by flooring type. Given the low representation of rubber floor and solid concrete floor in the original sample, some farms were included even if they failed to meet some of the items listed in the above criteria. Questionnaire replies, after 1 reminder, were obtained from 1,323 farmers, a response rate of $55 \%$. Of these 1,323 farms, 1,036 had freestall or loose housing systems and 268 had tiestalls.
From the 1,036 freestall or loose housing systems, 232 farms met the inclusion criteria. On these 232 farms, 2,335 cows were investigated. The total material available for descriptive and statistical analyses included 4,670 front and 4,670 hind legs. In total, 546 observations (legs) were dropped from the multivariable model because of missing information. This was due to mismatches between cow and herd identity. The descriptive data were based on 232 herds and the logistic model on 226 herds.

\section{Study Recordings}

The 232 herds were visited once during the period from September 2006 to June 2007 by 5 trained observers. The observers attempted to standardize data collection through an initial 2-d training session followed by 3 additional training sessions. Two of the observers, who conducted the majority $(73 \%)$ of the registrations, had regular meetings between farm visits to enhance the consistency of data recording. A systematic protocol was used to record data from every farm. Additionally, data were analyzed for a significant clustering effect of observer to ensure no significant differences in recording.

Recordings included a range of animal-based welfare indicators. Measurements made of individual cows included skin lesions, BCS, locomotion score, and shoulder height. The month in which the herds were visited was recorded, as was access to pasture in the summer period.

Animals studied in more detail during farm visits were selected by systematic random sampling. Every third to fifth animal, based on its unique individual identification number from the recording system, was selected depending on herd size at the time of the visit. Ten animals were studied per farm.

Lesions on the skin were recorded on both the left and the right legs at the following locations: knee (carpal joint), front code (fetlock joint), hock (tarsal joint), stifle joint (articulation genus), and hip (tuber coxae). Lesions were classified as 1) no skin change, 2) hairless, 3) swollen, 4) wound, or 5) open wound (Regula et al., 2004). Body condition scores were recorded as reported by Edmonson et al. (1989). Locomotion scoring was recorded according to Sprecher et al. (1997). In the statistical analysis, their 5-point locomotion score was transformed into a dichotomous variable and into a 4-category variable.

Data containing information about milk production and other detailed information about each cow such as parity and DIM were extracted from the Norwegian Dairy Herd Recording System (NDHRS) and are presented in Table 1. 
Table 1. Distribution of individual cow data available from 2006, according to the Norwegian Dairy Herd Recording System (NDHRS) of the 232 herds with the additional individual data registered during visits

\begin{tabular}{lcccc}
\hline Variable & Classification & Cows, n (\%) & Mean & SD \\
\hline Milk production $^{1}$ & & 2,335 & $7,052.8$ & 929.1 \\
DIM $^{1}$ & & 2,062 & 138 & 97.7 \\
Parity $^{1}$ & 1 & $718(30.8)$ & & \\
& 2 & $593(25.4)$ & & \\
& 3 & $655(15.6)$ & & 4.0 \\
Shoulder height $^{2,3} \mathrm{~cm}$ & $>3$ & 2,085 & & \\
BCS $^{2}$ & & 2,329 & & \\
Locomotion score $^{2}$ & 1 & $1,079(46.2)$ & & \\
& 2 & $863(37.0)$ & & \\
& 3 & $285(12.2)$ & & \\
\end{tabular}

${ }^{1}$ Data from NDHRS.

${ }^{2}$ Recorded during the visit to the indoor housing period from September 2006 to June 2007.

${ }^{3}$ Recorded by using a laser device attached to a centimeter scale to ensure that no physical contact was made with the animal.

The dimensions of the freestalls were recorded as illustrated in Figure 1. Measures of freestall base softness were not obtained on the farm visits, but different types of freestall base were classified into 3 groups according to the expected softness measured as millimeters impact of a sphere (diameter $=120 \mathrm{~mm}$ ) at $2 \mathrm{kN}$ load, a method used by the Deutsche LandwirtschaftsGesellschaft (DLG, 2009). Concrete was considered the hardest freestall base (group 1), compact rubber mats with a thickness between 15 and $30 \mathrm{~mm}$ as the second hardest (group 2), soft mats (30- to 40-mm thick) and mattresses (40- to $100-\mathrm{mm}$ thick) were classified as the softest (group 3). The last category, called mixed freestall base, included stall bases within more than one category; for example, rubber mats and concrete floors.

Type of bedding material was categorized into 4 main groups, where $1=$ none used, $2=$ sawdust, $3=\operatorname{wood}$

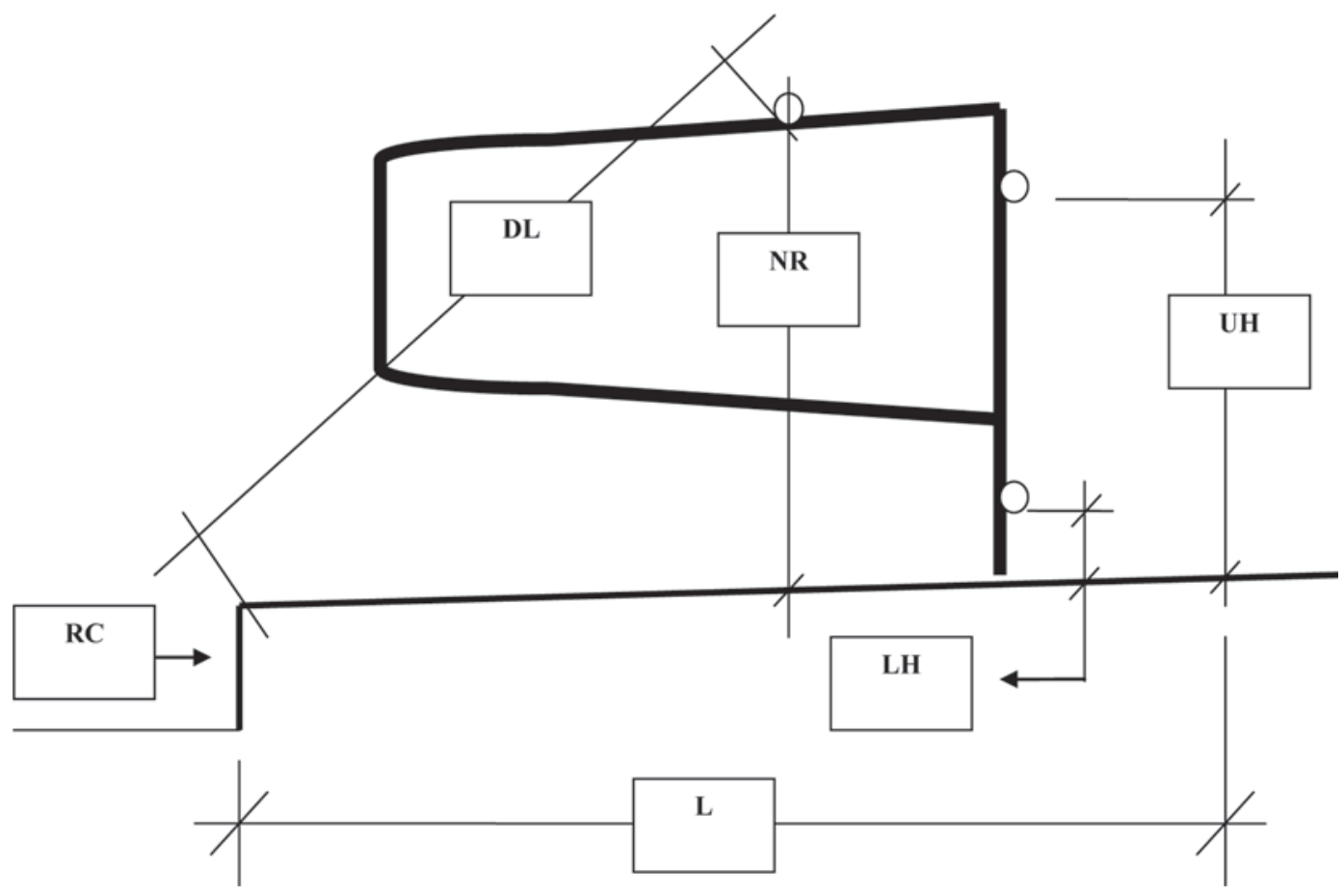

Figure 1. Dimensions $(\mathrm{cm})$ measured in the freestall: $\mathrm{L}=$ stall length; $\mathrm{LH}=$ lower head rail; $\mathrm{UH}=$ upper head rail; $\mathrm{RC}=$ rear curb height; $\mathrm{DL}=$ diagonal freestall length; and $\mathrm{NR}=$ neck rail height. 
shavings, and $4=$ other types (types that did not fit categories 1 to 3 ). Amount of bedding used per cow was based on answers given by the farmers at the time of the visit.

Farmers were asked to consider a statement, marking their answer on a 5-point Likert scale ranging from strongly disagree (1) to strongly agree (5). The statement was from Kielland et al. (2008): "Animals experience physical pain as humans do." Only 125 farmers $(54 \%)$ answered this question.

\section{Statistical Analysis}

Descriptive analysis of possible risk factors was performed before entering the data into the models. Missing data from the questionnaire about the attitude of the farmer was provided by adding one category with missing values to the attitude statement $(\mathrm{n}=1,822$ legs). Some of the BCS measurements were missing $(\mathrm{n}=8)$, and these were replaced with the mean BCS (2,335 observations). Missing data on shoulder height were accounted for by adding a technical yes-no variable and analyzing an interaction between this variable and the continuous shoulder height variable.

Given that there were 2 recordings for each individual (left and right leg) and 10 individuals in each herd, the cluster effect at the individual and herd level was included as a random effect using an alternating logistic regression with individuals nested within herd (Carey et al., 1993) using the SAS statement Proc GENMODE (version 9.1, SAS Institute Inc., Cary, NC). The general model used for estimating $\beta$ was

$$
\begin{aligned}
\operatorname{Logit}\left(\mathrm{p}_{\mathrm{i}}\right) & =\beta_{0}+\beta_{1} X_{1 i s}+\ldots+\beta_{k} X_{k i s} \\
& +\mathrm{z}_{\text {herd (i) }}+\mathrm{z}_{\text {individ (s) }},
\end{aligned}
$$

where $\beta_{0}$ is the intercept, $\beta_{1} X_{1 i s}+\ldots+\beta_{k} X_{k i s}$ are fixed effects, and $z_{\text {herd (i) }}+z_{\text {individ (s) }}$ are random effects due to herd and individual, respectively. This procedure was used to investigate risk factors related to the absence or presence of lesions on the legs of dairy cattle using a binomial distribution with a loglink function, and Wald chi-square type 3 for significance testing.

The outcomes chosen were any type of lesions on the knee in one model and hock lesions in a second model. Lesions were classified as hairless, swollen, wound or open wound (1), or no lesions (0). Linearity was investigated with basic graphs, and each variable was explored against each outcome individually. Continuous variables that did not have a linear relationship with the outcome were transformed to categorized variables according to their percentiles or quartiles $(10,25,50,75$, or $90 \%)$. Other variables were transformed into ordinary dummy variables or hierarchical dummy variables. First, each explanatory variable was tested separately, including random effects. Variables with a $P$-value $<0.20$ within this analysis were considered in the full model. When building up the full model, a forward stepwise technique was used, starting with the variables with the lowest $P$-values from the separate variable analyses. Thus, any distortion and confounding could be observed as each variable was included separately. Confounding variables were tested by running the model with and without that variable. The variables giving the best fit were chosen. If variables were correlated, only one of these variables was included. Goodness of fit for each model was evaluated with $\Delta$ deviance. The models were run with and without the variables attitude and lameness.

\section{RESULTS}

\section{Descriptive Analysis}

The main breed was Norwegian Red, which accounted for more than $90 \%$ of the animals sampled. Mean herd size was $38.6 \pm 15.5(\mathrm{SD})$. Table 1 presents individual cow data available for analysis in the logistic model.

The number of herds that had a solid concrete floors was $81(34.9 \%) ; 133(57.3 \%)$ had slatted floors and 18 $(7.8 \%)$ had rubber floors. One herd housed in freestalls milked cows in tie stalls, 193 farms used milking parlors $(83.2 \%)$, and 38 had an automatic milking system $(16.4 \%)$. Eleven herds $(6.9 \%)$ were on organic farms. Summer grazing from June to August was used by $60 \%$ of the farms sampled.

The distribution of the different severities of skin lesions is presented in Table 2. Lesions were mostly observed on the hock and knee joints with a prevalence of 60.5 and $35.3 \%$, respectively. Only 3 to $9 \%$ of cows had lesions on hips, fetlocks, and thighs. With regard to the hock recordings, $40 \%$ of the legs had no lesions, $53 \%$ had hair loss, $1.0 \%$ had swelling, and $6 \%$ had wounds. On the knee, $65 \%$ had no lesions, $29 \%$ had hair loss, $4.6 \%$ had swollen areas, only $1.4 \%$ had wounds, and no open wounds were found. Only $17 \%$ of the cows had locomotion scores of 3,4 , or 5 , and were defined as lame (Table 1).

The herd prevalence of skin lesions showed large variation regarding knee and hock locations. Hock lesions were present in all herds and 6 herds had a prevalence of $100 \%$, whereas for knee lesions 21 herds had no cows with lesions and only 1 herd had knee lesions on all cows. At the herd level, the limit for the lowest quartile for hock lesions (25\% of the herds) was $45 \%$ and that for the highest quartile ( $75 \%$ of the herds) was $75 \%$. Lesions on the knee showed a limit for the lowest quartile of $15 \%$ and the highest quartile of $55 \%$. 
Table 2. Number of observed skin lesions recorded in 2,335 cows $^{1}$

\begin{tabular}{lcrrrrc}
\hline Body location & No noticeable changes & Hair loss & Swollen & Wound & Open wound & Prevalence $^{2}$ \\
\hline Left knee & 1,513 & 668 & 122 & 32 & 0 & 0.35 \\
Right knee & 1,517 & 689 & 95 & 34 & 0 & 0.35 \\
Left fetlock joint & 2,268 & 50 & 8 & 9 & 0 & 0.03 \\
Right fetlock joint & 2,260 & 54 & 6 & 15 & 0 & 0.03 \\
Left hock & 897 & 1,280 & 27 & 130 & 1 & 0.62 \\
Right hock & 947 & 1,214 & 33 & 141 & 0 & 0.59 \\
Left thigh & 2,094 & 193 & 5 & 43 & 0 & 0.10 \\
Right thigh & 2,157 & 136 & 4 & 38 & 0 & 0.08 \\
Left hip & 2,279 & 47 & 3 & 6 & 0 & 0.02 \\
Right hip & 2,244 & 8 & 10 & 1 & 0.04 \\
\hline
\end{tabular}

${ }^{1}$ Different categories of skin lesions were observed at different body locations (presented for the left and right side).

${ }^{2}$ Prevalence of the total numbers of lesions in the skin, regardless of severity (hair loss, swollen, wound, open wound).

\section{Logistic Regression}

Table 3 lists the variables having no significant association with skin lesions. The results of the logistic regression analyses with risk factors significantly associated at the 2 locations with the highest prevalence, the knee and the hock, are in Table 4. Risk factors for skin lesions on the knee were attitude of farmer, 1 to 119 DIM, cow height, locomotion score $\geq 1$, bedding material, concrete, the length of lying area, and parity. Risk factors for skin lesions on the hock were left leg, farming style, month of visit, DIM from -60 to 59, BCS, lameness, parity, amount of bedding, freestall base, the length of lying area, and the diagonal length in freestall base. In general, risks for skin lesions on both knee and hock were associated with a hard freestall base, the length of lying area, and with older cows. Risk factors that differed for skin lesions on the knee and the hock were attitude of farmer, farming style, month of visit, cow height, lameness, BCS, and type and amount of bedding. Days in milk showed opposite odds ratios (OR) for knee lesions and hock lesions (Figure 2).

Regarding the model on knee lesions, 2,657 legs had no lesions and 1,467 legs had hair loss, swollen joints, or a wound. The covariates included in the model of the knee lesions explained $15.2 \%$ of the variation. The model on hock lesions included 1,602 legs with no lesions and 2,522 legs with hair loss, swollen joints, or a wound. The covariates in the hock lesions model explained $19.4 \%$ of the variation.

Table 3. Distribution of the variables that were tested in 2 independent models (alternating logistic regression), but found not significantly associated with the model for the knee lesions or hock lesion $(\mathrm{n}=4,124$ legs in each model)

\begin{tabular}{|c|c|c|c|c|}
\hline Variable & Classification & Legs, n (\%) & Mean & $\mathrm{SD}$ \\
\hline \multirow[t]{2}{*}{$\mathrm{AMS}^{1}$} & Yes & $652(15.8)$ & & \\
\hline & No & $3,472(84.2)$ & & \\
\hline \multirow{2}{*}{ Summer grazing $^{2}$} & Yes & $2,494(60.48)$ & & \\
\hline & No & $1,630(39.52)$ & & \\
\hline Herd size & Continuous & 4,124 & 38.6 & 15.5 \\
\hline Calving to calving interval & Continuous & 4,100 & 367.4 & 14.8 \\
\hline \multirow[t]{3}{*}{ Floor (alley) } & Solid concrete & $1,484(34.9)$ & & \\
\hline & Slatted floor & $2,352(57.6)$ & & \\
\hline & Rubber & $288(7.76)$ & & \\
\hline \multicolumn{5}{|l|}{ Freestall design } \\
\hline Diagonal $^{3}$ & $\mathrm{~cm}$ & 4,104 & 191.9 & 7.0 \\
\hline Rear curb height ${ }^{3}$ & $\mathrm{~cm}$ & 4,124 & 23.4 & 5.9 \\
\hline Neck rail $^{3}$ & $\mathrm{~cm}$ & 4,124 & 106.7 & 4.7 \\
\hline Width $^{3}$ & $\mathrm{~cm}$ & 4,124 & 113.8 & 2.0 \\
\hline Upper head rail ${ }^{3}$ & $\mathrm{~cm}$ & 2,290 & 90.7 & 15.2 \\
\hline Lower head rail ${ }^{3}$ & $\mathrm{~cm}$ & 2,008 & 37.6 & 17.4 \\
\hline \multirow[t]{2}{*}{ Brisket board $^{3}$} & Yes & 996 & 31.8 & \\
\hline & No & 3,128 & 68.2 & \\
\hline
\end{tabular}

${ }^{1}$ Automatic milking system.

${ }^{2}$ Summer grazing: farmers were asked if their cows were outdoors during the summer period.

${ }^{3}$ Detailed measurements from the free-stall design. 
Table 4. Estimates for significant risk factors in the final logistic model with lesions on the knee in one model and lesions on the hock in a separate model

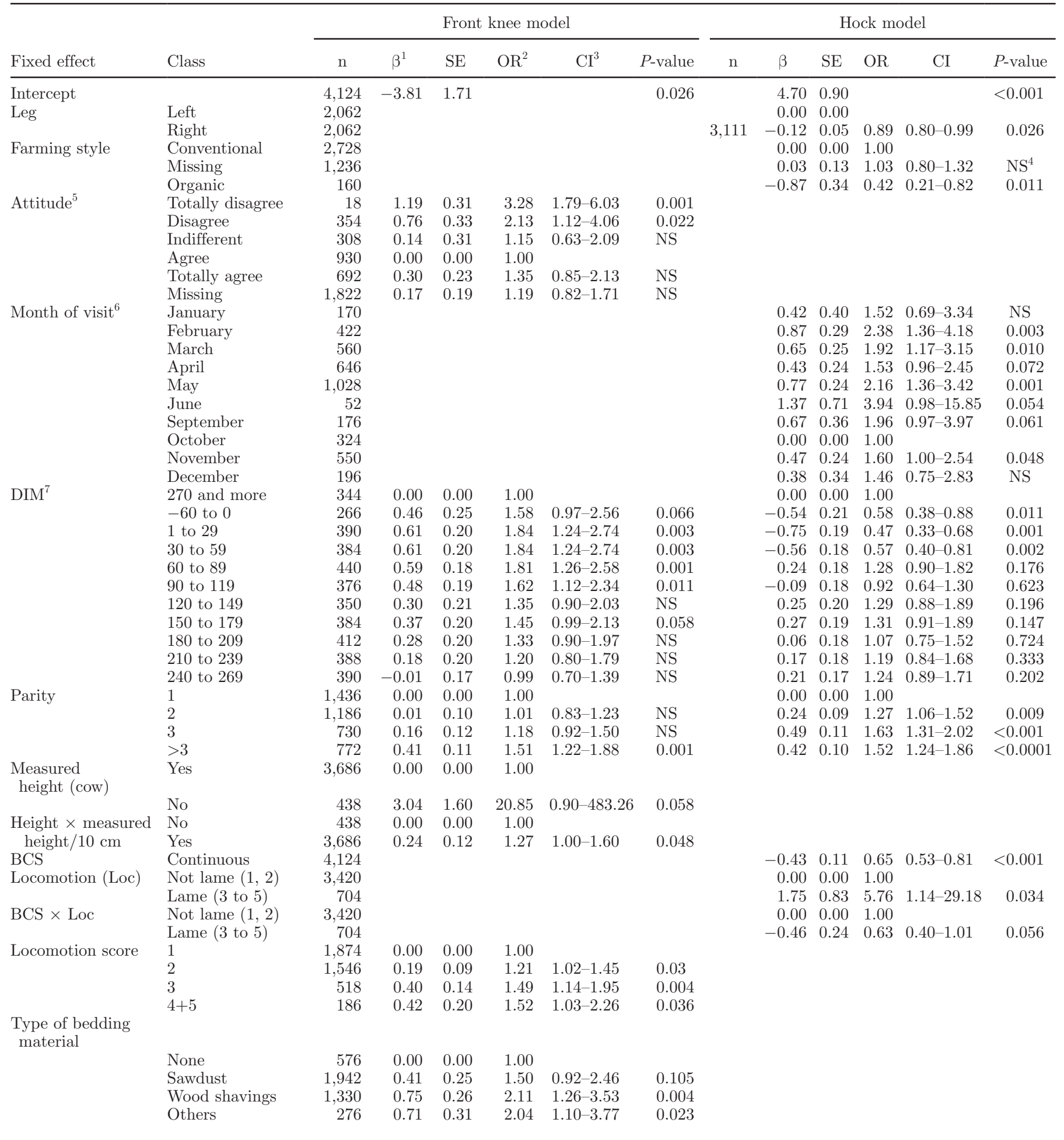


Table 4 (Continued). Estimates for significant risk factors in the final logistic model with lesions on the knee in one model and lesions on the hock in a separate model

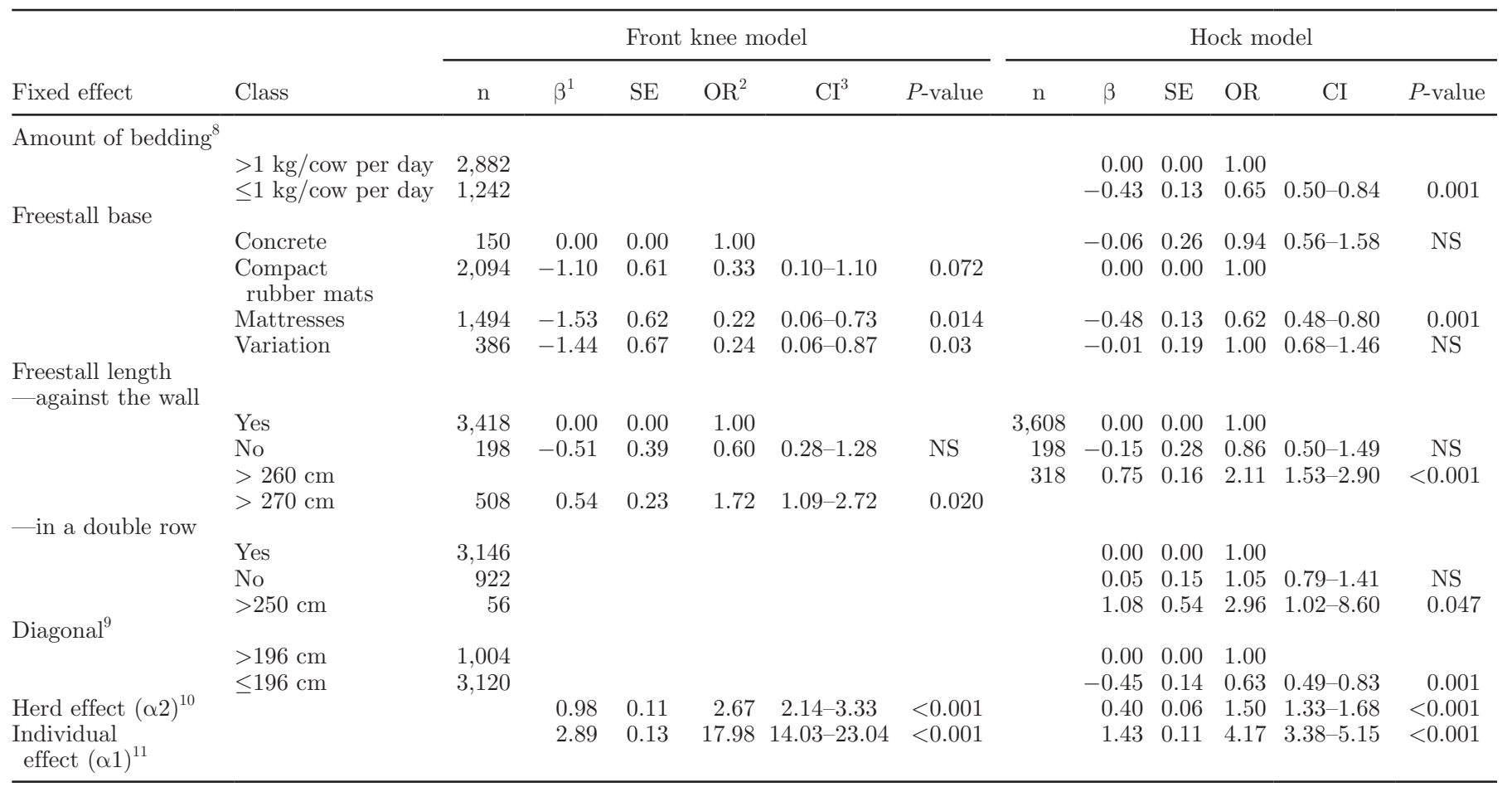

${ }^{1}$ Estimate.

${ }^{2}$ Odds ratio.

${ }^{3}$ Confidence interval, lower and upper limits.

${ }^{4} \mathrm{NS}=P>0.10$.

${ }^{5}$ Farmers' assessment of the statement "Animals feel physical pain as humans do" on a 5-point scale, from totally disagree to totally agree (Kielland et al., 2008).

${ }^{6}$ When the farm was visited (month) in the indoor housing period, September 2006 to June 2007.

${ }^{7} \mathrm{DIM}$ on the day of registration.

${ }^{8}$ Farmers were asked about how much bedding they used per year and that number was divided by number of days and number of dairy cattle at that farm.

${ }^{9}$ Detailed measurements from the freestall design (Figure 1).

${ }^{10} \alpha 2=$ random effect on herd level.

${ }^{11} \mathrm{\alpha} 1=$ random effect on individual cow level.

When investigating clustering within the individual cow, the model concerning lesions on the knee revealed an OR of 18.0, which indicated a large individual correlation between the 2 front legs. This effect was less extreme regarding the lesions on the hock $(\mathrm{OR}=4.2)$. The cluster effect revealed an OR of 2.7, indicating an individual correlation between the cows within herds with regard to lesions on the knee. This effect was lower regarding the lesions on the hock $(\mathrm{OR}=1.5)$.

Farmers who disagreed and totally disagreed with the statement "Animals feel physical pain as humans do" were at high risk of having cows with lesions on the knee compared with farmers who agreed with this statement. This association was not found with lesions on the hock. Including the answers from the statement in the knee model, the cluster effect at herd level was reduced by $3.9 \%$ (from 2.78 to 2.67 ). A significantly better fit was achieved by including the attitude of the farmer, and the model explained $1.7 \%$ more of the variation when comparing a reduced model with a full model including the answers to the statement.

\section{DISCUSSION}

The prevalence of changes of all kinds on the skin of the hock was high, and our data supported Canadian studies (Weary and Taszkun, 2000) but was lower than that reported by Main et al. (2003) in the UK. Skin lesions on the knee had a prevalence that supported reports on 113 farms in 5 states in the United States 


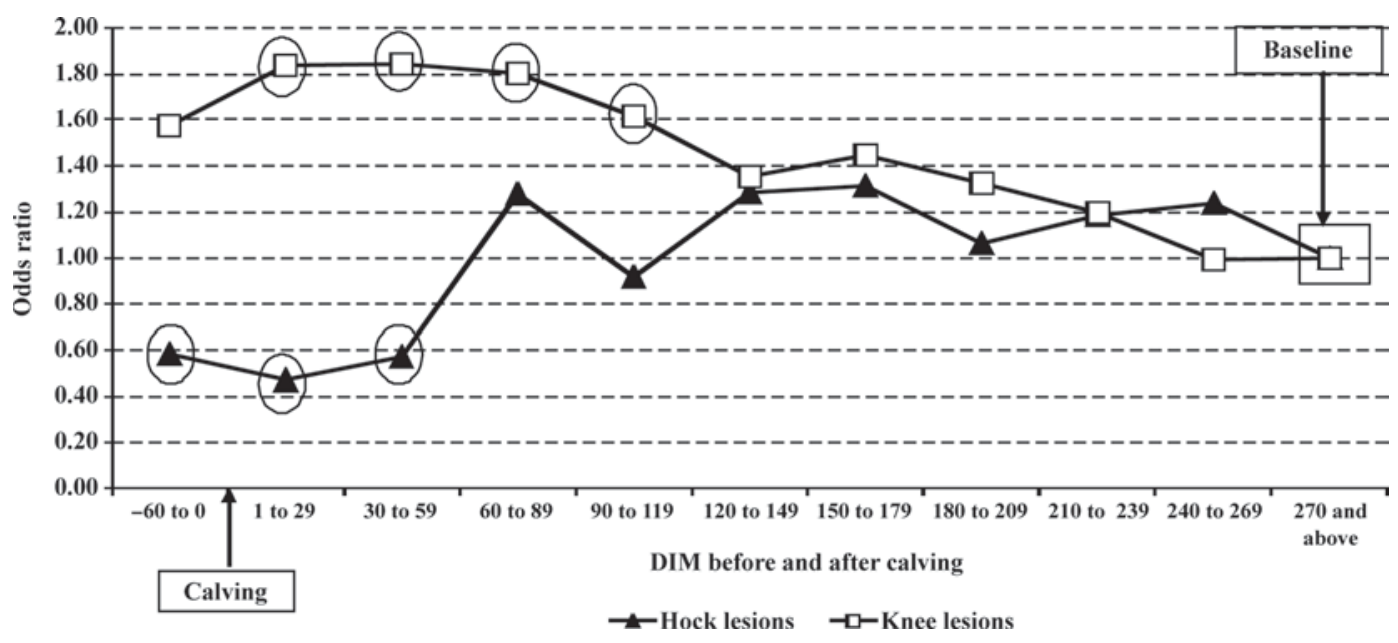

Figure 2. Odds ratios (OR) of hock and knee lesions in relation to DIM. The OR are from 2 separate and independent logistic models, one for knee lesions and one for hock lesions. $P$-values $<0.05$ are circled; baseline in both models was the category $270 \mathrm{~d}$ and above.

(Wisconsin, Minnesota, Indiana, Iowa, New York; Fulwider et al., 2007).

Our data suggest that risk factors associated with skin lesions differ according to the location of the lesion, supporting the results of Rushen et al. (2007) and Zurbrigg et al. (2005). In contrast to previous work, we analyzed both left and right feet within the same model, taking care of the repeated measurement by having "individual" as a random effect in the model. In this way, a correlation could be demonstrated between the findings on left and right legs and not only the fixed effect.

Lameness could have similar risk factors as skin lesions and could confound the results. When lameness was included as a fixed variable, the other estimates barely changed and the direction of the estimates stayed the same. Therefore, lameness was included in the full model. The attitude variable was tested with the same approach, and only minor changes in the estimates and standard error occurred. This indicated that these 2 variables, despite being of another source of variability in addition to stall design, added information to the models and contributed to the explanation of variation of the prevalence of skin lesions on the leg.

A significant difference between left and right sides $(\mathrm{OR}=0.89)$ was found in the hock model but not in the knee model. In addition to the anatomic differences (e.g., presence of protrusion) between the knee and hock, the normal lying behavior of cows (e.g., both knees simultaneously in contact with the floor) could help to explain these findings. These differences in use and anatomy might explain why taller (assumed to be heavier) cows have more lesions on the knee, regardless of BCS, and why cows with higher BCS have fewer lesions on the hock regardless of height. These differences might explain why the correlation within and between cows on knee lesions was much higher $(\mathrm{OR}=2.7$ and 18.0) than on hocks ( $\mathrm{OR}=1.5$ and 4.2). Inferences about causality might be that cows have to put both knees on the floor at almost the same time when lying down or standing up. They also lie down with both of their front legs touching the underlying surface.

Some aspects of freestall design were associated with skin lesions. In contrast to studies in Canada (Weary and Taszkun, 2000) and in Switzerland (Keil et al., 2006), which reported that longer stalls decreased the prevalence of lesions on hocks, we found that cows on farms with longer stalls $(>260 \mathrm{~cm})$ had higher occurrence $(\mathrm{OR}=2.11)$ of hock lesions. The difference in findings might be because of the longer stalls used in Canada and because the study in Switzerland was carried out in tie stalls. Another reason might be that the hock is situated outside the freestall base when the cow lies down in shorter stalls. Based on our model, upper head rails, rear curb heights, neck rails, widths, and brisket boards were not associated and these factors were excluded.

From January 1, 2006, the Norwegian regulations on keeping cattle (Norwegian Food Authorities, 2004) required that cows have a soft freestall base. Some farmers had not been able to change the freestall base by the time the current study was performed and still had concrete as the freestall base. Concrete is hard and very abrasive, and more lesions on the legs were expected and found. Cows from herds with compact rubber mats $(\mathrm{OR}=0.33)$ or mattresses $(\mathrm{OR}=0.22)$ had fewer lesions on the knee, and mattresses $(\mathrm{OR}=0.62)$ were associated with fewer lesions on the hock compared with compact rubber mats. These findings support previous studies, which reported that replacing mats with mattresses reduced the risk of hock damage (Livesey et al., 2002). Mattresses may improve cow comfort and lying 
time (Chaplin et al., 2000; Anderson, 2008). A soft freestall base reduced the prevalence of hock damage by $17 \%$ compared with a hard freestall base in a study conducted in Germany and Austria (Brenninkmeyer et al., 2008). In our study, a soft freestall base was the best of the materials identified. Some studies have reported that sand, waterbeds, and deep litter might be better at reducing the risk of leg lesions (Livesey et al., 2002; Norring et al., 2008), but these types of freestall base are rarely encountered in Norwegian dairy farms.

The attitude of the farmer plays a major role in managing animals (Anderson, 2008). A simple answer to one statement in a questionnaire does not give a full attitude profile, but it may offer some insight into how farmers handle their animals. Even considering the limited scope of the question asked, there was an association between attitudes toward animals and the occurrence of lesions on the knee. Difference in distributions of knee lesions and hock lesions indicated that there were more possibilities for reducing the risk with regard to knee lesions, offering possible ways to address the issue. It was demonstrated previously that attitudes affect how humans treat farm animals (Coleman et al., 1998). This might explain part of the role the farmers have regarding risk factors. That the estimate of the herd effect (Table 4) was reduced by including this statement in the model supports this argument.

\section{CONCLUSIONS}

The large variation in prevalence between herds indicated that improvement is possible if risk factors are identified. In general, risks for skin lesions on legs of cows were associated with a hard freestall base, the length of the lying area, and with parity. Risk factors that differed between the locations of skin lesions were the attitude of farmer, farming style, month of visit, cow height, DIM, and type and amount of bedding. These results demonstrate that freestall design is important with respect to skin lesions as are characteristics of individual animals and the farmer.

\section{ACKNOWLEDGMENTS}

The authors thank the farmers for their participation and the technicians Hans Kristian Hansen and Stine Kvivesen, employed by Norwegian School of Veterinary Science for 3 and $1 \mathrm{yr}$, respectively, for their help and support during the trial. The access to data was given by the Norwegian Dairy Herd Recording System and the Norwegian Cattle Health Services in agreement number $3 / 2006$. The study was financially supported by grants from the Research Council of Norway (15\%), Agricultural Agreement Research Fund (16\%), and the
Foundation for Research Levy on Agricultural Products $(69 \%)$.

\section{REFERENCES}

Anderson, N. 2008. Dairy cow comfort-Cow behaviour to judge free stall and tie stall barns http://www.omafra.gov.on.ca/english/ livestock/dairy/facts/info_cowbehave.htm Accessed Feb. 2, 2009.

Brambell Committee. 1965. Report of the Technical Committee to Enquire Into the Welfare of Animals Kept Under Intensive Livestock Husbandry Systems. Her Majesty's Stationery Office, London, UK.

Brenninkmeyer, C., S. Dippel, J. Brinkmann, S. March, C. Winckler, and U. Knierim. 2008. Risk factors for hock lesions in cubicle housed dairy cows in Germany and Austria. Page 48 in Proc. 4th International Workshop on the Assessment of Animal Welfare at Farm and Group level (WAFL), Vienna, Austria.

Busato, A., P. Trachsel, and J. W. Blum. 2000. Frequency of traumatic cow injuries in relation to housing systems in Swiss organic dairy herds. J. Vet. Med. Ser. A 47:221-229.

Carey, V. I. N. C., S. L. Zeger, and P. E. T. E. Diggle. 1993. Modeling multivariate binary data with alternating logistic regressions. Biometrika 80:517-526.

Chaplin, S. J., G. Tierney, C. Stockwell, D. N. Logue, and M. Kelly. 2000. An evaluation of mattresses and mats in two dairy units. Appl. Anim. Behav. Sci. 66:263-272.

Coleman, G. J., P. H. Hemsworth, and M. Hay. 1998. Predicting stockperson behaviour towards pigs from attitudinal and jobrelated variables and empathy. Appl. Anim. Behav. Sci. 58:6375 .

DLG. 2009. DLG Test Reports. http://www.dlg.org/stall. html\#Liegebox Accessed Mar. 1, 2009.

Edmonson, A. J., I. J. Lean, L. D. Weaver, T. Farver, and G. Webster. 1989. A body condition scoring chart for Holstein dairy cows. J. Dairy Sci. 72:68-78.

Fulwider, W. K., T. Grandin, D. J. Garrick, T. E. Engle, W. D. Lamm, N. L. Dalsted, and B. E. Rollin. 2007. Influence of free-stall base on tarsal joint lesions and hygiene in dairy cows. J. Dairy Sci. 90:3559-3566.

Hemsworth, P. H., G. J. Coleman, J. L. Barnett, and S. Borg. 2000. Relationships between human-animal interactions and productivity of commercial dairy cows. J. Anim. Sci. 78:2821-2831.

Huxley, J., and H. R. Whay. 2006. Cow based assessments. Part 2: Rising restrictions and injuries associated with the lying surface. UK Vet. 11:1-6.

Keil, N. M., T. U. Wiederkehr, K. Friedli, and B. Wechsler. 2006. Effects of frequency and duration of outdoor exercise on the prevalence of hock lesions in tied Swiss dairy cows. Prev. Vet. Med. 74:142-153.

Kielland, C., E. Skjerve, O. Østerås, and A. J. Zanella. 2008. Dairy farmers' assessment of animal pain, using a photo-based instrument, can predict animal welfare outcomes at farm level. Page 226 in Proc. 42nd Congr. Int. Soc. Appl. Ethol., Dublin, Ireland.

Livesey, C. T., C. Marsh, J. A. Metcalf, and R. A. Laven. 2002. Hock injuries in cattle kept in straw yards or cubicles with rubber mats or mattresses. Vet. Rec. 150:677-679.

Main, D. C., H. R. Whay, L. E. Green, and A. J. Webster. 2003. Effect of the RSPCA Freedom Food Scheme on the welfare of dairy cattle. Vet. Rec. 153:227-231.

Norring, M., E. Manninen, A. M. De Passillé, J. Rushen, L. Munksgaard, and H. Saloniemi. 2008. Effects of sand and straw bedding on the lying behavior, cleanliness, and hoof and hock injuries of dairy cows. J. Dairy Sci. 91:570-576.

Norwegian Food Authorities. 2004. Regulations for keeping cattle. In Norwegian: Forskrift om hold av storfe, http://www.lovdata.no/ cgi-wift/ldles?doc=/sf/sf/sf-20040422-0665.html Accessed Feb. 1, 2009.

Regula, G., J. Danuser, B. Spycher, and B. Wechsler. 2004. Health and welfare of dairy cows in different husbandry systems in Switzerland. Prev. Vet. Med. 66:247-264. 
Rushen, J., D. Haley, and A. M. De Passillé. 2007. Effect of softer flooring in tie stalls on resting behavior and leg injuries of lactating cows. J. Dairy Sci. 90:3647-3651.

Rutherford, K. M., F. M. Langford, M. C. Jack, L. Sherwood, A. B. Lawrence, and M. J. Haskell. 2008. Hock injury prevalence and associated risk factors on organic and nonorganic dairy farms in the United Kingdom. J. Dairy Sci. 91:2265-2274.

Sogstad, A. M., T. Fjeldaas, and O. Osteras. 2005. Lameness and claw lesions of the Norwegian red dairy cattle housed in free stalls in relation to environment, parity and stage of lactation. Acta Vet. Scand. 46:203-217.
Sprecher, D. J., D. E. Hostetler, and J. B. Kaneene. 1997. A lameness scoring system that uses posture and gait to predict dairy cattle reproductive performance. Theriogenology 47:1179-1187.

Weary, D. M., and I. Taszkun. 2000. Hock lesions and free-stall design. J. Dairy Sci. 83:697-702.

Zurbrigg, K., D. Kelton, N. Anderson, and S. Millman. 2005. Stall dimensions and the prevalence of lameness, injury, and cleanliness on 317 tie-stall dairy farms in Ontario. Can. Vet. J. 46:902-909. 